\title{
BMJ Open How do adolescent girls and boys perceive symptoms suggestive of endometriosis among their peers? Findings from focus group discussions in New York City
}

\author{
Jhumka Gupta, ${ }^{1}$ Lauren F Cardoso, ${ }^{2}$ Courtney S Harris, ${ }^{1}$ Arielle D Dance, ${ }^{3}$ \\ Tamer Seckin, ${ }^{4}$ Nina Baker, ${ }^{4}$ Yvonne O Ferguson ${ }^{5}$
}

To cite: Gupta J, Cardoso LF, Harris CS, et al. How do adolescent girls and boys perceive symptoms suggestive of endometriosis among their peers? Findings from focus group discussions in New York City. BMJ Open 2018;8:e020657. doi:10.1136/ bmjopen-2017-020657

- Prepublication history and additional material for this paper are available online. To view these files, please visit the journal online (http://dx.doi. org/10.1136/bmjopen-2017020657).

Received 15 November 2017 Revised 21 February 2018 Accepted 20 April 2018

Check for updates

${ }^{1}$ Department of Global and Community Health, College of Health and Human Services, George Mason University,

Fairfax, Virginia, USA

${ }^{2}$ School of Social Policy and Practice, University of Pennsylvania, Philadelphia, Pennsylvania, USA

${ }^{3}$ College of Integrative Medicine and Health Sciences, Saybrook University, Oakland, California, USA

${ }^{4}$ Endometriosis Foundation of America, New York, USA ${ }^{5}$ GetQualitative, Washington DC, USA

Correspondence to

Dr Jhumka Gupta;

jgupta4@gmu.edu

\section{ABSTRACT}

Objective Symptoms of endometriosis, including pelvic pain, back and nerve pain, and gastrointestinal pain, often begin in adolescence. Yet, research on the experience of these debilitating symptoms among young people is scarce. Of particular concern is the influence of adolescent girls' social context. This study qualitatively examined how, among adolescents, endometriosis and symptoms suggestive of endometriosis is perceived at the family, peer/school and community/society levels.

Design Eight focus groups were conducted; vignettes were used to elicit participants' perceptions of factors that may shape girls' experiences of endometriosis. Data were analysed using constant comparison analysis.

Participants An ethnically diverse sample of girls and boys ages $14-18(n=54)$ residing in New York City.

Results Fifteen themes emerged and were distilled to eight cross-cutting factors that influence perceptions of endometriosis at different levels of the ecological model: distrust of community healthcare providers, societal stigma of menstruation, peer stigma of endometriosis symptoms, distrust of school healthcare providers, lack of endometriosis knowledge among peers and school personnel, inequitable gender norms, invisibility of symptoms and the stigma of teen sex among parents. Further, these factors may compound symptoms' impact on individual girl's social, educational and emotional wellbeing.

Conclusions Findings underscore the importance of understanding the social environment of girls experiencing symptoms suggestive of endometriosis and educating and engaging their peers, family and school personnel to create a supportive, informed social climate. Efforts should specifically include stigma reduction campaigns targeted towards female and male adolescents.

\section{INTRODUCTION}

Endometriosis, a chronic condition characterised by cells similar to the uterine lining that exist outside of the uterus, ${ }^{1}$ is estimated to impact $10 \%$ of women of reproductive age. $^{2}$ In the USA, that approximates to some
Strengths and limitations of this study

- This is the first study to examine how social context may impact the social, educational and medical experiences of adolescent girls with symptoms suggestive of endometriosis.

- Focus groups with an ethnically diverse sample of adolescent girls and boys residing in New York City allowed for capturing diverse perspectives on perceptions of endometriosis.

- The use of vignettes facilitated conversation on a stigmatised health issue.

- The main limitation is that the study used a convenience sample of adolescents recruited through non-profit leaders and teachers with an interest in the topic, which may have biased the sample towards participants with more willingness to discuss topics related to women's health.

7.4 million women. ${ }^{3}$ Symptoms of endometriosis may include painful, heavy or irregular menstruation; bowel and urinary disorders; back and pelvic pain; dyspareunia; nerve pain and infertility. ${ }^{4-8}$ Endometriosis has been documented to adversely impact multiple aspects of women and girls' lives. Symptoms diminish physical functioning (eg, mobility, sleep), ${ }^{9-11}$ emotional well-being (eg, depression and anxiety) ${ }^{512} 13$ and social well-being (eg, social isolation and missed social activities). ${ }^{14-16}$ Women have also reported educational and professional disruptions ${ }^{17}$ with one study estimating an average of 19.3 missed work days annually. ${ }^{18}$ Lost wages, coupled with healthcare expenses, result in a substantial economic burden on women. ${ }^{18}$

Diagnostic delays, stigma and lack of support collectively contribute to the toll endometriosis has on quality of life and social, emotional and economic well-being. 
Time to diagnosis ranges from 2 to 12 years, and can be three times longer for women whose onset of symptoms occurred during adolescence. ${ }^{1029}{ }^{20}$ Such delays can be partially attributed to the health sector's inadequacy in addressing endometriosis. Women commonly report that prior to diagnosis doctors have minimised, normalised or dismissed their symptoms ${ }^{41-23}$ and have inappropriately referred or misdiagnosed them. ${ }^{15}{ }^{24}$ Beyond the healthcare sector, interactions with partners, family members, friends and other elements of a woman's social context can influence diagnostic delays and the support received. For instance, when partners trivialise symptoms, women are less willing to seek help, ${ }^{25}$ although supportive partners can be an integral source of care. ${ }^{22} 2627$ The broader family environment further shapes women's experiences with endometriosis. Qualitative research has also found that familial cultural norms can require women to 'endure' and keep pain private, and that increased household resources can improve women's agency in help-seeking. ${ }^{23}$ More broadly, social norms consider menstruation as something to conceal. ${ }^{25} 28$ These norms are sustained by the actions of men and women in social, professional and medical spheres, thus further discouraging women from seeking help.

Despite growing recognition that endometriosis symptoms often begin in adolescence, research with adolescent populations is scarce. The few existing studies have largely focused on clinical/surgical outcomes,${ }^{29-33}$ with little attention to social context. One notable exception is the Menstrual Disorder of Teenagers study, which investigates menstrual disorders, including endometriosis, but does not examine perceptions of symptoms or the social context within which they are experienced. ${ }^{34}$ The social influence of peers, family and community on health and help-seeking behaviours during adolescence has been well-documented for numerous adolescent health issues (eg, dating violence, ${ }^{35}$ obesity, ${ }^{36}$ substance use, ${ }^{3738}$ sexual risk ${ }^{39}$ ). Adolescence is a period of developmental transition when young people are particularly affected by contextual influences, ${ }^{40}$ thus understanding how adolescents view endometriosis, including the manifestation of such symptoms among peers, can provide much needed data to inform evidence-based messaging for public health initiatives. Such research is consistent with the recently published priorities in endometriosis research ${ }^{4142}$ as such data can provide an opportunity to positively influence the trajectory of those who may be suffering from this disease. Thus, the current study aims to qualitatively examine how endometriosis and its symptoms are perceived at the family, peer/school and community/societal levels among an ethnically mixed sample of adolescent boys and girls.

\section{METHODS}

\section{Overview}

Eight gender-specific focus group discussions (FGDs) were conducted with adolescents $(\mathrm{N}=54)$ residing in
New York City (NYC). Vignettes were used to explore perceptions of symptoms suggestive of endometriosis, how these symptoms may impact different aspects of girls' lives and help-seeking opportunities. The vignettes and discussion questions were also designed to examine perceptions of endometriosis at family, peer/ school and community/societal levels ${ }^{43}$ to elicit factors that potentially shape girls' experiences of endometriosis symptoms.

\section{Participants}

The research was conducted in collaboration with a NYC-based non-profit organisation focused on endometriosis advocacy. Programme staff sent an initial email introducing the study to NYC public school and community-based organisation (CBO) administrators in their network, with purposeful focus on schools and $\mathrm{CBO}$ with diverse ethnicities and socioeconomic backgrounds. Interested administrators were then sent materials on study procedures and required NYC Department of Education (DOE) documentation.

Administrators of participating CBOs introduced the study to all eligible participants. At NYC schools, a health teacher announced the opportunity to take part in a study on perceptions of menstrual health to all eligible students in their class or afterschool group. Eligible participants were ages 14-18, English speaking and cognitively abled at the high-school level.

Eight FGDs were conducted, five with girls $(n=38)$ and three with boys $(n=16)$. Half of the FGDs took place in NYC public schools and the other half took place in NYC-based CBOs.

\section{Vignettes}

Four vignettes were used to elicit participants' perceptions of the experiences of girls with endometriosis-like symptoms. Due to low awareness of endometriosis, menstrual stigma and the study's focus on adolescents, vignettes were used for facilitating FGDs. Vignettes are recognised as an effective means to stimulate group discussion around sensitive/stigmatised health topics with youth. ${ }^{44}$ Each vignette centred on the story of one adolescent female with a specific set of endometriosis symptoms in a social situation common to this age group (see table 1). With low endometriosis awareness among adolescents, participants were not initially told that the characters' symptoms were indicative of endometriosis. Vignettes were developed through literature review and feedback from experts and patients to portray the most common endometriosis symptoms and relatable social situations. Specifically, after crafting the vignettes, we invited review and comments from experts and patients. Revisions based on this feedback included, for example, better expressing the severity of symptoms (eg, we added 'feeling like being stabbed with a knife' to vignette $1)$. Vignettes were pilot-tested with three groups of participants (two female groups and one male group) 


Vignette title
Amanda and her
sports team

Dominique and her good grades

\section{Text of vignette}

Amanda is the captain of the varsity volleyball team. She loves to stay active and work out with her teammates. But whenever Amanda gets her period she bleeds very heavy causing her to pass out. She says she feels like someone is stabbing, especially feeling like being stabbed with a knife, the inside of her stomach, legs, and lower back. The first time she passed out at a volleyball game, everyone assumed it was due to exhaustion or dehydration, but even after drinking enough water, this kept happening. Amanda noticed that these episodes kept happening almost every period, and so she had to miss practice and a few games. She told her teammate, Kelly, who then told Amanda to 'quit being such a girl' and toughen up.

It's November and Dominique has already missed 10 days of school and her grades are suffering. Previously a straight-A student, it is really tough for her to struggle this much. Around her period, Dominique has severe pain in her belly making it hard for her to walk, stand, and even sit at times, so she has to stay home from school, or leave school early. The school nurse sent a note to her parents saying that she is concerned that Dominique is exaggerating her symptoms since almost all teenage girls get cramps, and that she doesn't look ill.

\begin{tabular}{|c|c|}
\hline $\begin{array}{l}\text { Sam and her } \\
\text { relationship }\end{array}$ & $\begin{array}{l}\text { Clayton really likes his girlfriend, Sam. They have } \\
\text { been dating for almost a year and have had sex a } \\
\text { few times. Sometimes when they have sex, Sam } \\
\text { cries afterwards. Clayton wonders if it's something } \\
\text { he's doing wrong. Sam eventually told him that sex } \\
\text { hurts her stomach and it doesn't feel good to her. } \\
\text { She also told him that she feels sharp pains in her } \\
\text { lower stomach for a few days after they have sex, } \\
\text { and she vomits as well. }\end{array}$ \\
\hline $\begin{array}{l}\text { Bianca and her } \\
\text { Quinceañera }^{63 *}\end{array}$ & $\begin{array}{l}\text { Bianca has her Quinceañera coming up, and she } \\
\text { is very excited about that. She has a gorgeous } \\
\text { dress picked out and her family is planning a } \\
\text { big party for her. However, Bianca has also been } \\
\text { having a lot of pain. She is confused because the } \\
\text { pain feels like someone is stabbing her when she } \\
\text { poops. This pain with pooping is worse when she } \\
\text { is on her period, and she has even passed out } \\
\text { while pooping. As her Quinceañera approaches, } \\
\text { Bianca figures out that she will be on her period } \\
\text { during that time and worries that she won't be } \\
\text { able to enjoy her big day because of the pain and } \\
\text { pooping. She feels too embarrassed to share these } \\
\text { worries with her family, so she just keeps it to } \\
\text { herself. }\end{array}$ \\
\hline
\end{tabular}

Sam and her Clayton really likes his girlfriend, Sam. They have been dating for almost a year and have had sex cries afterwards. Clayton wonders if it's something he's doing wrong. Sam eventually told him that sex hurts her stomach and it doesn't feel good to her. ( and she vomits as well.

is very excited about that. She has a gorgeous dress picked out and her family is planning a big party for her. However, Bianca has also been having a lot of pain. She is confused because the pain feels like someone is stabbing her when she poops. This pain with is worse when she while pooping. As her Quinceañera approaches, Bianca figures out that she will be on her period during that time and worries that she won't be able to enjoy her big day because of the pain and worries with her family, so she just keeps it to herself.

\section{Symptoms suggestive of endometriosis}

Heavy bleeding, To explore the perceptions stabbing pain, passing of what a girl in Amanda's out situation may face at the peer and school level, with particular attention to extracurricular activities, such as sports, and the individuallevel consequences of such interactions
Debilitating cramps

Painful sex, vomiting

Painful bowel movements
To examine teens' perceptions of what Dominique might experience, in light of her symptoms, grades and interaction with the nurse, within the school and at home recruited by CBOs to ensure participants' comprehension. Following the pilot, some terms were revised so that they were better understood by participants and the number of questions following each vignette was reduced to keep the discussion within the 90 minute time frame.

\section{To explore teens' perceptions of what a girl with these symptoms may experience in relation to her peers, parents and in a healthcare setting.}

*A Quinceañera is a Latin American tradition of celebrating a girl's 15th birthday. 


\section{Data collection}

The 90-minute FGDs were conducted by a graduate student with prior training in facilitation and women's health research. A second graduate student served as a note-taker. All FGDs were held in private areas within schools and/or CBOs during the 2015-2016 school year. The semistructured interview guide contained one general health question, the four vignettes and related questions, and a demographic questionnaire (see online supplementary appendix for the FGD guide).

Written parental consent was obtained for participants under 18 years old. The facilitator began FGDs by reviewing assent and consent forms and inviting participants to sign, followed by an explanation that the discussion would cover issues related to menstrual health. She then reiterated that participant information would be kept confidential, discussions would be audio recorded, they could choose a pseudonym to conceal actual names and they could quit participating at any time without consequence. Finally, the facilitator set some ground rules for the discussion, which included respecting each other by not interrupting the person talking, waiting to be called on and feeling comfortable agreeing or disagreeing with fellow participants. She stressed that there were no right or wrong answers. All participants provided written informed consent/assent before FGDs; refreshments were provided. The facilitator opened the discussion with a general health question before proceeding to the vignettes. A short synopsis introducing the character and her symptom(s) preceded each vignette. The facilitator then read the vignette aloud one to two times, and discussion questions followed. At the end of the FGDs, handouts were provided with information on endometriosis. Participants requesting additional information regarding suspected endometriosis were directed to the section of the handouts containing support resources.

\section{Analysis}

FGDs were audio recorded and transcribed verbatim. The transcripts were entered into ATLAS.ti V.7, a computer software program designed for the coding and analysis of qualitative data. ${ }^{46}$ The study team created a codebook that described each code and when it should be applied and each transcript was topically coded. To assess interrater reliability, two team members independently coded a transcript and then compared codes resolving discrepancies and revising as needed. ${ }^{47}$ Inter-rater reliability was $87.8 \%$, exceeding the a priori criteria of $85.0 \% .^{48} 49$ Constant comparison analysis strategies, aided by visual displays, were used to analyse participants' responses. ${ }^{4-51}$ This method involved data generated from FGDs to support emerging categories and themes. Early FGD data were coded, and as more data were collected, these codes were revised. Organising the analysis by each vignette, the team assessed what topics generated the most discussion, agreement and disagreement related to participants' perceptions of adolescents' experiences with endometriosis-like symptoms, across all eight focus

\begin{tabular}{|c|c|c|}
\hline Characteristic & $\mathbf{N}$ & $\%$ \\
\hline Total & 54 & 100.0 \\
\hline \multicolumn{3}{|l|}{ Gender } \\
\hline Female & 38 & 70.4 \\
\hline Male & 16 & 29.6 \\
\hline Median age (SD) & $16(1.16)$ & - \\
\hline \multicolumn{3}{|l|}{ Race/ethnicity } \\
\hline Hispanic/Latino/a & 22 & 40.7 \\
\hline White & 14 & 25.9 \\
\hline Black/African-American & 8 & 14.8 \\
\hline Asian & 5 & 9.3 \\
\hline Mixed & 5 & 9.3 \\
\hline \multicolumn{3}{|l|}{ Birthplace } \\
\hline USA & 46 & 85.2 \\
\hline Other & 8 & 14.8 \\
\hline \multicolumn{3}{|c|}{ Number of parents born outside of the USA } \\
\hline 0 & 19 & 35.2 \\
\hline 1 & 8 & 14.8 \\
\hline 2 & 27 & 50.0 \\
\hline
\end{tabular}

groups. Fifteen emerging themes, operating at multiple levels of the social environment, were developed from clustering codes that appeared to fit with one another and comparing these themes of responses between focus groups and between male and female adolescents. These analytic steps continued until no new themes emerged and were documented using audit trail methodology. ${ }^{52}$ Themes were organised by symptom (in the text) and further by level of the social ecological model (in the diagram) in order to align with a public health approach to understanding a health concern and strategising for prevention and intervention.

\section{Patient and public involvement statement}

Participants were not involved in the design of this research. The design was informed, however, by the knowledge and experience of endometriosis patients and experts. Study results will be shared with teachers and CBO administrators who will then be able to share results with study participants.

\section{RESULTS}

Participant demographics are displayed in table 2. Findings and themes are detailed below. Figure 1 also illustrates how these themes, which are cross-cutting and can be distilled to eight major factors, are situated at the family, peer/school and community/societal levels of the social ecological model. Further, this diagram highlights the perceived impact of endometriosis symptoms on the lives of individual girls. 


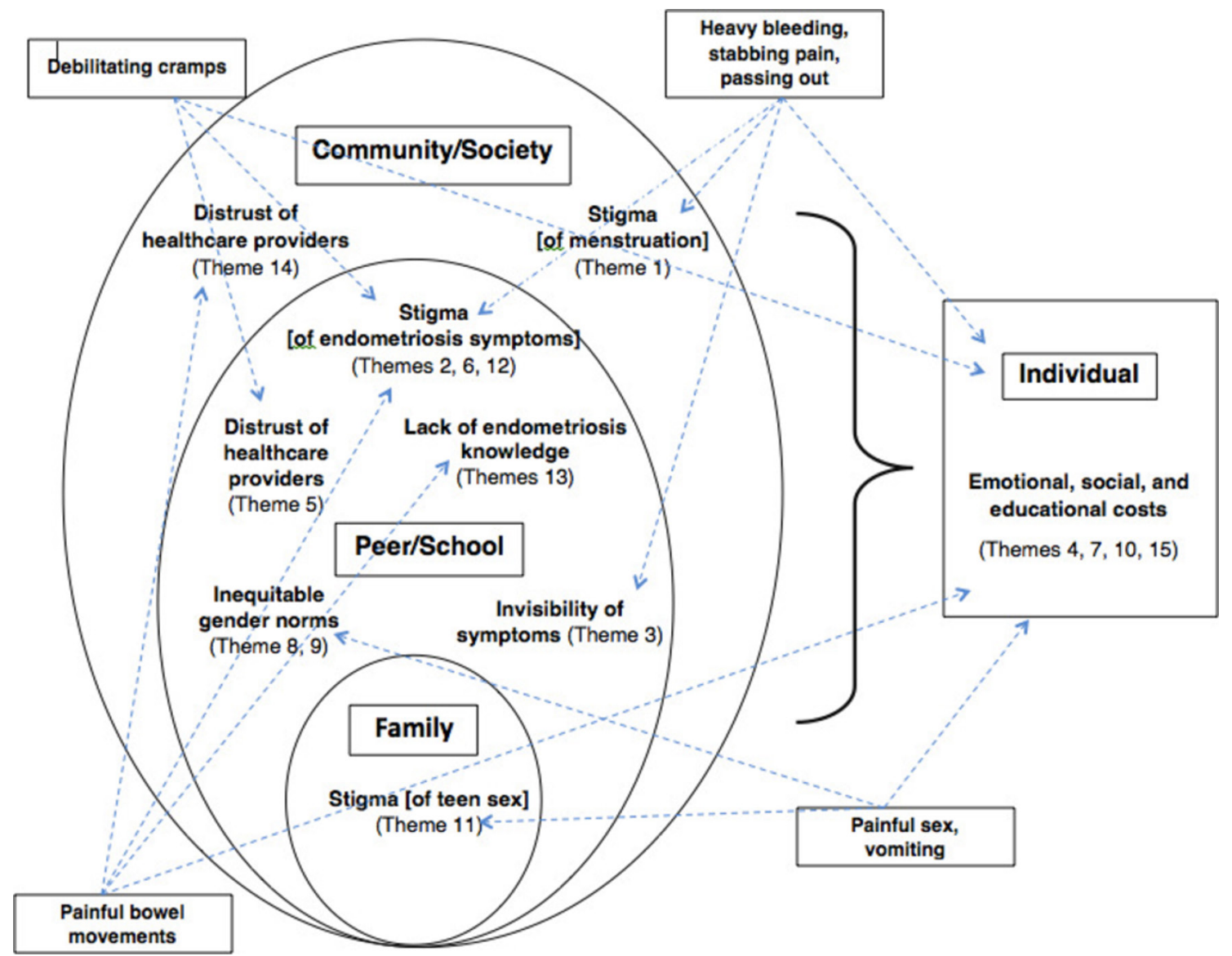

Figure 1 Factors shaping perceptions of symptoms of endometriosis.

\section{Vignette: Amanda}

Theme 1: menstrual stigma can prevent help-seeking

Across groups, there was consensus that menstruation is stigmatised. Participants discussed how periods are often associated with weakness and considered taboo because they concern a female health issue and female anatomy. As one female participant said:

It's the fact that women don't like to talk about having their period because, alright, because it's gross to men. And men don't like to hear it and men are the more dominant people in society, and if a man doesn't like it being talked about then women are not going to talk about it in front of people in general. And so it's kind of seen as taboo to talk about your period. Something that has to do with your vagina, that's taboo you can't talk about that you know? (Female, FG 4)

This stigma stymies conversation about menstruation generally and can extend to endometriosis symptoms. This is particularly the case in a school environment, where participants linked lack of menstrual health education with girls' fear of discussing such issues. One female participant stated, 'Some girls find out about their periods when they actually get them. It's just never talked about in schooling' (female, FG 4). Another added, 'Your period is not really, it's so scientifically talked about in our health classes ... and some people have questions, but they're too ashamed or scared to ask them, which is terrible' (female, FG 4).

Theme 2: compounded stigma faced by female athletes

Athletes experiencing endometriosis symptoms may be particularly vulnerable to stigma and lack of understanding from peers and teammates due to sports being equated with strength. According to participants, a female high school athlete would be subject to ridicule if she 'didn't pull her weight' during her period. Additionally, as an inherently competitive person, she may hold herself to unrealistic expectations and try to push through unbearable pain. In both cases, either "protecting her integrity as an athlete or trying not to be targeted, she would probably be less willing to share' (female, FG 4) her symptoms, particularly with her teammates.

Theme 3: 'invisible' symptoms influence perceptions of suffering Participants reported a broad lack of knowledge about the heterogeneity in period experiences and the extreme pain and discomfort girls with symptoms of endometriosis may face. Consequently, girls with symptoms of endometriosis can find social environments to be unsupportive and unsympathetic. This sentiment was expressed when participants were asked to consider whether Amanda's teammates would respond similarly ('toughen up, stop 
being such a girl') if Amanda had diabetes versus debilitating cramps. For instance, a participant said:

I think in this case, she would actually understand because diabetes is more common (compared to endometriosis). Instead of like, saying toughen up she would, understand and tell her to seek support. Because she's aware of the consequences of having diabetes. (Male, FG 6)

This quote is emblematic of the belief that girls are more likely to receive support for health issues that they perceived as more commonly discussed. As multiple participants stated, pain associated with severe cramps is not measurable nor visible, and therefore can be subject to more disbelief than symptoms that appear in plain sight.

\section{Theme 4: self-doubt and isolation}

Participants discussed how girls with experiences similar to Amanda's may feel isolated because of lack of understanding. Additionally, girls may begin to question their own perceptions of symptoms. As one participant expressed, a girl facing repeated disbelief may start to 'feel like they're overreacting, even though everything they're saying is valid in terms of their body and what they are feeling' (female, FG 7). Such self-doubt, which becomes reinforced by peers, could inhibit future help-seeking.

\section{Vignette: Dominique}

Theme 5: lack of training among school personnel

Participants overwhelmingly expressed that school nurses would lack the ability to help a girl with Dominique's symptoms. They perceived nurses as having only the capacity to treat minor health problems, with limited knowledge and resources for addressing more complex issues such as what Dominique presented with. One participant stated:

Certain diseases have certain symptoms and you can't just tell by looking, you have to really dig into it to find out what the person has and talk with the person. But, in most cases [the nurse] just checks you for your, maybe blood pressure, fever, the temperature and if these are ok, then they probably just think you're fine. (Male, FG 6)

Without proper training, nurses would fail to recognise endometriosis signs and may perceive girls like Dominique as just exaggerating their menstrual symptoms. In both the boys and girls FGDs, it was expressed that nurses would also be suspicious because students in their schools commonly exaggerate illnesses to get out of class. As one participant said,

Also if you're [the] school nurse you're probably used to kids having ulterior motives for illnesses and I think she's probably experienced a lot of cases where the student [is] trying to get out of class. So if a girl comes to her with a thing that happens to every girl most of the time, she [would] probably just assume she's trying to get out of class. (Male, FG 5)

In terms of help-seeking, male and female participants differed on whom they thought may be the best source of support. Male participants felt that reaching out to a trusted male, including a male healthcare provider, would be more effective for receiving care and empathy because men cannot relate to endometriosis symptoms and might therefore be more apt to act. They further felt that female caregivers may be more likely to normalise endometriosis symptoms and dismiss them. As one participant from focus group 3 said,

The school nurse [feels] like she understands Dominque's pain, so it's like, 'oh it's nothing, I've gone through the same thing.' She's like, 'Oh I know this already. There's no way her pain is that bad.' So, at some point the school nurse would feel like she can relate to Dominque and so it's just like, 'Oh, she'll get over it. It's nothing.' (Male, FGD 3)

Female participants, on the other hand, more often indicated female family members and healthcare providers as the most effective supporter because they would feel most comfortable speaking with a woman (who has experience with reproductive health issues) about such sensitive topics. However, as indicated above, consistent doubts were expressed about the likelihood of receiving the needed care from the school nurse.

Theme 6: comparisons between endometriosis symptoms and mental health

Several participants drew broad parallels between the stigma of mental health issues, like depression, with the stigma of endometriosis symptoms. They perceived both to be less understood, less believed and taken less seriously than other health problems. After asking participants if they thought the nurse would have responded differently to Dominique if she had a different health issue, one girl responded, 'Uh, for depression maybe not because mental health, like women's health, like the menstrual cycle, is not really taken seriously, it's not a visible injury' (female, FG 4). A few dissented, however, making the case that mental health issues are increasingly discussed in schools. Moreover, as one participant states, mental health affects boys and girls:

If she had been like diagnosed with depression instead of like endometriosis I think that the nurse would've taken it much more serious. Depression can happen to both females and males while endometriosis can only happen to females so I think that depression everyone is educated on like the symptoms or the after-effects but only half of the population even - not even, a quarter of the population would learn about the effects of endometriosis and what it can do to a person. So I think that the nurse would definitely have treated her differently if it was depression, you know? (Female, FG 4) 
Theme 7: educational costs of symptoms of endometriosis and psychological distress

Both boys and girls expressed that missing school as a result of severe menstrual pain would have implications for girls' mental health. They described how it would be 'frustrating', 'depressing' and 'devastating' to work hard in school but have grades suffer due to uncontrollable and debilitating symptoms. One participant put herself in Dominique's shoes saying, 'I would feel mad like because there's something that's going on with my body that's stopping me from doing my work and to me education is like everything' (female, FG 2). Beyond immediate repercussions, participants also suggested that girls in Dominique's position may face longterm consequences of missing school and dropping grades as it relates to attending college and fulfilling other future goals. Another participant stated,

Personally, I take my grades very, very seriously so I have a 4.0 and I like to keep it that way and I don't know it's just a personal thing but if they were to drop I would feel like my whole life is in danger. I know it's not, but it's just a personal thing. I would feel very anxious. I would feel very afraid for my future ... So my grades going down [would] seriously affect how I think of myself (Female, FG 4)

\section{Vignette: Sam}

Theme 8: painful sex and social isolation

Participants discussed how girls experiencing symptoms such as painful sexual intercourse would feel alone and different from peers. As one participant describes, girls are expected to enjoy sex and those who do not may feel isolated and ashamed,

It's not normal to have pain after sex, you know? Maybe the first time there may be pain, but sex is supposed to be pleasurable for both parties. If one person is feeling pain as opposed to pleasure they're kind of ashamed of telling [anyone] because you know sex is supposed to be fun, it's supposed to be good. But I'm not feeling good about this you know so I'm ashamed to tell someone that sex doesn't feel right to me. (Female, FG 4)

Theme 9: gender norms inhibit discussion of painful sex with male partners

One of the most salient themes across all groups was that a girl experiencing painful sex would have many reservations about sharing her experiences with her boyfriend. Participants agreed that anticipation of a boy's negative response may force her to hide discomfort. For instance, one participant shared,

[Sam won't communicate with her boyfriend about experiencing painful sex] because probably she feels like, he might think that she got an STI or something. Because sometimes, when you do have sex with somebody, and you have a [sexually transmitted] disease, it hurts so ... he might judge her. She's hesitant, or uncomfortable because, she's probably afraid of the response or of how he would react. (Female, FG 1)

She may also be afraid of hurting his feelings. As a participant said,

If you tell your boyfriend it hurts when we're having sex, it is like saying 'you're not doing it right.' For guys, they're like really sensitive towards those types of [sexual performance] conversations. So when they're having sex, they want to be good at it. So what would happen if she did tell him? It goes two ways, it's either, he tries to fix the problem or, he leaves her. (Female, FG 1)

Participants suggested that a boyfriend in this situation would likely gossip, cheat on or break up with Sam. Girls may thus endure painful sex and other endometriosis-related symptoms silently due to fear of social consequences.

Sam wants to please her boyfriend, but even though she knows that it's gonna hurt, she kinda just wants to, like, sit there and take it, because she wants to please her boyfriend. (Female, FG 1)

\section{Theme 10: painful sex and girls' fear of gossip}

Study participants discussed how high school gossip about sex is commonplace, and thus intimate details about a girl's sex life could easily be spread among peers. Participants expressed that if Sam told her boyfriend the whole school could find out:

I know guys tend to not think, and they tell that their girlfriend does not like sex to a friend, and this friend goes to tell another friend, and this friend goes to another friend and then somehow Sam ends up hearing that somehow this person that you've never really spoken to in your entire life, knows that you don't like sex. You just don't want to be put in that position where someone will ever come up to you and be like, 'Wait are you the person who doesn't like sex?' That's just something that would be your worst nightmare. (Female, FG 1)

The shame of 'not enjoying' sex was perceived to socially isolate girls, prompting them to question their body and sexual ability, and preventing them from seeking support from others. As one participant said:

I feel like it's just kind of embarrassing ... Because other girls can take it. They can have sex and not feel anything. So there must be something wrong with you. So I must be doing something wrong, or there must be something wrong in my body to make me feel this way (Female, FG 1)

Theme 11: attitudes towards teen sex inhibit discussion with adult caregivers about painful sex

Fear of parental judgement was another salient theme. Specifically, participants believed that Sam would not disclose to her parents (or other family members) her 
experience of having painful sexual intercourse because of the stigma related to teenage sex. One participant explained, however, that this could vary, depending on parents' cultural beliefs and attitudes towards premarital sex:

It depends on culture because there are some parents that are like 'just use a condom that's all that's all I care about.' And so in that case, Sam could just ask them, 'Yeah I'm having pain while having intercourse and I don't know what to do. So we should go to a doctor?' ... Whereas, if it's like parents that are very traditional, like wait until marriage [to have sex], then it's a totally different case cause you can't talk about anything. You would just be afraid to explain or tell them anything and so if there's like a significant problem you won't be able to tell them. (Male, FG 3)

\section{Vignette: Bianca}

Theme 12: gastrointestinal symptoms and ridicule from peers

When asked if a girl could talk to her friends about her endometriosis symptom of painful bowel movements, groups responded with a resounding 'No!' Participants stated that it would be embarrassing to disclose these symptoms to friends. As one participant said, 'Having a problem like that ... that's like, embarrassing ... I'm pooping, uncontrollably, and then [they're] probably gonna laugh, you're probably gonna laugh, so I'll probably feel like embarrassed to tell them' (female, FG 1). Another stated, 'I think [Bianca] was afraid of how people would judge her. [Her friends] would probably be like "Um that's nasty yo"' (female, FG 2). This discomfort played out within FGDs as well; discussions were filled with nervous laughter and giggling with indications of being less forthcoming and willing to engage with questions related to Bianca's experience.

\section{Theme 13: peers unable to relate to debilitating gastrointestinal symptoms}

Though participants were less forthcoming in this vignette, they did discuss how they felt they would not be able to help Bianca. Participants discussed how they had very little knowledge to offer:

Her friends would probably be like, 'What's wrong with her? Why is she even going through something like that? I wouldn't think to try to help Bianca or anything, I would just I don't know what I would do'. (Female, FG 1)

Theme 14: girls distrust healthcare providers to respect them and take their health issues seriously

While participants were less expressive with this vignette compared with others, they did share their perceptions that healthcare providers would not be helpful with gastrointestinal symptoms. Female participants agreed that they would be embarrassed to share these symptoms with a healthcare provider. One participant voiced her distrust when she said,

I would be embarrassed to tell the doctor because, I know doctors and stuff, and they go home and they might say, 'I had a patient, and she told me something is wrong with her pooping all the time [laughter].' I don't want to share, because [the doctor] is gonna share with other people. (Female, FG 1)

Further, female participants felt that doctors do not take their health issues seriously and offer quick fixes, instead of thoroughly treating a problem and taking the time to explain it:

I feel like doctors, because like, [there are] so many patients outside, or things get like overcrowded or whatever, so they have to [make things] fast ... and you tell them a problem, they find a fast fix, instead of going really deep into the issue. (Female, FG 1)

\section{Theme 15: gastrointestinal symptoms can impact girls' social functioning}

Participants believed that a girl in Bianca's situation would experience a range of emotions-shame, anger, sadness. Cancelling a party you are looking forward to because of these symptoms would make a girl feel sad and frustrated because she wouldn't be able to talk to her friends about the problem. On the other hand, if the party were to take place, a girl like Bianca would feel extremely stressed about potential health complications. When asked how they thought Bianca felt, one participant said

Embarrassed ... because [she would have to] go to the bathroom every two seconds. I would be embarrassed cause like what if I worked so hard to have a party and then can't go to it anymore? (Female, FG 2)

\section{DISCUSSION}

This is the first study to consider how adolescent girls and boys perceive symptoms suggestive of endometriosis within social and school settings. Study findings underscore the importance of social context in both influencing adolescents' perceptions of endometriosis symptoms as well as impacts on help-seeking and emotional health. Furthermore, study findings document how factors across the multiple levels of the social ecological model, such as societal-level stigma and peer-enacted inequitable gender norms, shape the types of support available to adolescent girls who may experience endometriosis symptoms.

Study findings are broadly consistent with existing research with social interactions experienced by adult women living with endometriosis. For instance, similar to the prevailing gender norms described by adolescents in the current study, adult women have described experiencing endometriosis within a broader social context that stigmatises and dismisses menstrual health. ${ }^{923}$ Seear $^{25}$ 
argues that the cultural representation of menstruation as a shameful experience meant to be concealed is a primary impediment to help-seeking among women with endometriosis. Women in Seear's study concealed symptoms due to fear of ostracism; many who disclosed to family, friends or coworkers faced judgement and disbelief. The treatment of menstruation as shameful, as Seear describes, is culturally specific and seemed to be salient with many of the participants in our focus groups. Adolescents described this judgement and disbelief within peer circles, intimate relationships, in school settings and with health professionals/school nurses.

Similar to adult women with endometriosis, ${ }^{15} 16$ adolescents in the current study discussed feelings of devastation at the prospect of missing educational or social opportunities due to a poorly understood illness. Research with adult women has also documented economic and work productivity impacts of endometriosis. ${ }^{17} 18$ Academic and social disturbances have been documented in relation to menstrual symptoms among adolescent girls ${ }^{34}$; however, further investigation of the impact of symptoms suggestive of endometriosis on adolescents is needed. This may include developing measures to assess school-based absenteeism and presenteeism due to endometriosis and its symptoms, wages missed for caregivers and adolescent girls who are employed, social costs (eg, missing important events, extracurricular activities) and medical costs. Such research can provide a fuller picture on the burden of endometriosis on society and thus inform policy.

The nexus of gender norms and disbelief of endometriosis symptoms were particularly problematic within the context of adolescent sexual relationships. Current findings echo research with adult women and their intimate relationships. Specifically, adult women reported that painful sexual experiences were a source of tension with partners ${ }^{16}$ as some partners falsely interpreted pain as an excuse to abstain from intercourse, ${ }^{25}$ while some women endured pain to avoid feeling guilt or inadequacy. ${ }^{15} 53$ Adolescents in the current study discussed how girls would feel compelled to conceal symptoms and endure painful sex due to fear of negative social consequences (eg, being shamed or accused of having a sexually transmitted infection). Such fear may be indicative of inequitable power dynamics, where girls hold less power relative to males regarding sexual communication. The importance of addressing gender norms and equity to improve girls' reproductive health has been well-documented $^{54} 55$ and has gained considerable traction in programming and advocacy efforts. To date, however, very little research and programming has explicitly considered how the interplay between pre-existing reproductive health issues and symptoms (eg, painful sex, nausea due to endometriosis), gender norms and invisible illness may also increase adolescent girls' vulnerability to sexual coercion. Researchers examining gendered power within relationships have called for situational analysis of the factors that influence girls' ability to control their sexual encounters and by extension, their health. ${ }^{56}$ Having a stigmatised and little known condition such as endometriosis may be among these critical factors shaping girls' decision-making power. More research is needed in this arena as existing research has documented a higher prevalence of intimate partner violence against adult women with debilitating chronic illness and disability. ${ }^{5758}$ Greater research and programmatic attention addressing gender roles, endometriosis symptoms and sexual autonomy in adolescence may help promote healthier relationships in adulthood.

The current study has several limitations. The study used a convenience sample of adolescents recruited through teachers, principals and non-profit leaders who expressed an interest in the topic. Thus, the sample may have been biased towards participants with more willingness to discuss topics related to women's health. While this promoted rich conversation, findings may not reflect perspectives of adolescents with less exposure to such issues. Recruitment was facilitated by school administrators, teachers and CBO personnel. As a result, it was not possible to calculate a response rate for this study. FGDs were facilitated in English, thus non-English speakers were not represented. Notably, this is among the few endometriosis-focused studies that have focused on recruiting populations of colour and thus extends the inclusiveness of the existing body of research. ${ }^{59}$ This study was the first of its kind to use vignettes. While vignettes facilitated conversation by providing participants with concrete, relatable stories, research is needed to examine how elicited responses may compare to more conventional approaches. Discussion of bowel symptoms was met with discomfort, thus more research is needed on how to elicit responses from adolescents regarding this symptom. Moreover, the hesitancy to discuss such symptoms may indicate the extreme stigma that must be addressed to more fully engage adolescents. Vignettes were also developed based on input from adult women with an endometriosis diagnosis who recalled their adolescent experiences. Thus, there may be additional vignettes that are more reflective and relatable to current adolescent social contexts (eg, social media). Nevertheless, the vignettes were well-received during piloting with adolescent girls and boys. Additionally, the discussions were designed to elicit participants' perceptions not their individual experiences. However, we recognise that these experiences likely influenced their perceptions of the scenarios discussed in the focus groups. Despite trying to create an environment that allowed for debate, there were not many dissenting opinions. This is a limitation of the study. Future research should investigate these dynamics further. Finally, while participants' level of engagement with the discussion topics were consistent across groups, some discussions produced quotes with more clarity and concision. Therefore, the quotes are not evenly distributed, but still reflect salience across all groups.

These limitations notwithstanding, the current study has important implications for future research and public health programming directions for endometriosis 
among adolescents. Findings clearly underscore a need to inform adolescents, their peer networks, their families, their schools and the health sector, about endometriosis and its symptoms. Moreover, given the interplay of stigma and gender discussed in FGDs, such information must be accompanied with stigma reduction efforts. Similar to other stigmatised health issues impacting adolescents (eg, poor mental health, sexual health), information alone is rarely sufficient. ${ }^{60} 61$ Such campaigning must reach various levels (individual, peer, etc) to foster supportive social climates. Importantly, these efforts cannot solely target girls and must engage male peers. As seen with other public health efforts to address gender norms, such as those related to teen dating violence or safe sex, engaging men and boys is essential for effective attitude and behaviour change related to gendered phenomena. ${ }^{62}$

In addition to informational and de-stigmatisation campaigns, findings suggest the importance of engaging peers, school personnel and family members in identifying symptoms. Further research is needed on the development of validated screening tools and referral protocols that can be used in social and otherwise non-medical settings (eg, schools, athletic teams, peers). Validated screening tools must also be developed for use by medical and healthcare professionals, such as school nurses, to assist with identification and referral. There is also a need to develop validated measures to assess the population-wide burden of symptoms suggestive of endometriosis in adolescent populations for surveillance purposes. Similarly, measures are needed to assess societal attitudes towards endometriosis and its symptoms. The development and use of these measures can help monitor and evaluate efforts to determine potential attitudinal shifts. It is hoped that with increased research and evidence-based programming the public health field can begin to address the critical issue of endometriosis, and thus promote physical and social well-being within this population.

Acknowledgements The authors acknowledge and thank the community organisations, teachers and principals who supported this study and believed in its importance. They also thank all of the adolescents who participated in the focus groups. They also like to thank Kate Young, PhD (candidate) of Monash University, for her helpful review of study vignettes.

Contributors JG conceptualised the study. JG, LFC and ADD created the focus group guides. TS and NB helped facilitate data collection and assisted with interpretation;.LFC and ADD led data collection. JG, LFC, CH and YOF conducted data analysis. and JG, LFC and CC drafted manuscript. All authors contributed feedback and approval of final manuscript.

Funding The authors have not declared a specific grant for this research from any funding agency in the public, commercial or not-for-profit sectors

Competing interests None declared.

Patient consent Not required.

Ethics approval All study protocols were approved by institutional review boards at George Mason University (854148-5), NYC DOE (1193) and Jewish Home Lifecare.

Provenance and peer review Not commissioned; externally peer reviewed.

Data sharing statement Due to the sensitive nature of the data, they are not publicly available, but are available on request.
Open Access This is an Open Access article distributed in accordance with the Creative Commons Attribution Non Commercial (CC BY-NC 4.0) license, which permits others to distribute, remix, adapt, build upon this work non-commercially, and license their derivative works on different terms, provided the original work is properly cited and the use is non-commercial. See: http://creativecommons.org/ licenses/by-nc/4.0/

(c) Article author(s) (or their employer(s) unless otherwise stated in the text of the article) 2018. All rights reserved. No commercial use is permitted unless otherwise expressly granted.

\section{REFERENCES}

1. Kennedy S, Bergqvist A, Chapron C, et al. ESHRE guideline for the diagnosis and treatment of endometriosis. Hum Reprod 2005;20:2698-704.

2. Viganò P, Parazzini F, Somigliana E, et al. Endometriosis: epidemiology and aetiological factors. Best Pract Res Clin Obstet Gynaecol 2004;18:177-200.

3. Age and sex composition: 2010 Census Briefs. 2011 https://www. census.gov/prod/cen2010/briefs/c2010br-03.pdf (accessed 25 Sep 2017).

4. Culley L, Law C, Hudson N, et al. The social and psychological impact of endometriosis on women's lives: a critical narrative review. Hum Reprod Update 2013;19:625-39.

5. De Nardi PD, Ferrrari S. Deep Pelvic Endometriosis: $A$ Multidisciplinary Approach: Springer Science \& Business Media, 2011.

6. Lemaire GS. More than just menstrual cramps: symptoms and uncertainty among women with endometriosis. J Obstet Gynecol Neonatal Nurs 2004;33:71-9.

7. Pluchino N, Wenger JM, Petignat $P$, et al. Sexual function in endometriosis patients and their partners: effect of the disease and consequences of treatment. Hum Reprod Update 2016;22:762-74.

8. Yantiss RK, Clement PB, Young RH. Endometriosis of the intestinal tract: a study of 44 cases of a disease that may cause diverse challenges in clinical and pathologic evaluation. Am J Surg Pathol 2001;25:445-54.

9. Jones CE. The Pain of Endo Existence: Toward a Feminist Disability Studies Reading of Endometriosis. Hypatia 2016;31:554-71.

10. Nnoaham KE, Hummelshoj L, Webster P, et al. Impact of endometriosis on quality of life and work productivity: a multicenter study across ten countries. Fertil Steril 2011;96:366-73.

11. Petrelluzzi KF, Garcia MC, Petta CA, et al. Salivary cortisol concentrations, stress and quality of life in women with endometriosis and chronic pelvic pain. Stress 2008;11:390-7.

12. Chen LC, Hsu JW, Huang KL, et al. Risk of developing major depression and anxiety disorders among women with endometriosis: A longitudinal follow-up study. J Affect Disord 2016;190:282-5.

13. Lorençatto C, Petta CA, Navarro MJ, et al. Depression in women with endometriosis with and without chronic pelvic pain. Acta Obstet Gynecol Scand 2006;85:88-92.

14. Fagervold $B$, Jenssen $M$, Hummelshoj $L$, et al. Life after a diagnosis with endometriosis - a 15 years follow-up study. Acta Obstet Gynecol Scand 2009;88:914-9.

15. Jones G, Jenkinson C, Kennedy S. The impact of endometriosis upon quality of life: a qualitative analysis. J Psychosom Obstet Gynaecol 2004;25:123-33.

16. Moradi M, Parker M, Sneddon A, et al. Impact of endometriosis on women's lives: a qualitative study. BMC Womens Health 2014;14:123.

17. Gilmour JA, Huntington A, Wilson HV. The impact of endometriosis on work and social participation. Int J Nurs Pract 2008;14:443-8.

18. Fourquet J, Báez L, Figueroa M, et al. Quantification of the impact of endometriosis symptoms on health-related quality of life and work productivity. Fertil Steril 2011;96:107-12.

19. Greene R, Stratton $P$, Cleary SD, et al. Diagnostic experience among 4,334 women reporting surgically diagnosed endometriosis. Fertil Steril 2009;91:32-9.

20. Hadfield $\mathrm{R}$, Mardon $\mathrm{H}$, Barlow $\mathrm{D}$, et al. Delay in the diagnosis of endometriosis: a survey of women from the USA and the UK. Hum Reprod 1996;11:878-80.

21. Cox H, Henderson L, Andersen N, et al. Focus group study of endometriosis: struggle, loss and the medical merry-go-round. Int $J$ Nurs Pract 2003;9:2-9.

22. Denny E. Women's experience of endometriosis. J Adv Nurs 2004;46:641-8.

23. Markovic M, Manderson L, Warren N. Endurance and contest: women's narratives of endometriosis. Health 2008;12:349-67. 
24. Ballard K, Lowton K, Wright J. What's the delay? A qualitative study of women's experiences of reaching a diagnosis of endometriosis. Fertil Steril 2006;86:1296-301.

25. Seear K. The etiquette of endometriosis: stigmatisation, menstrual concealment and the diagnostic delay. Soc Sci Med 2009;69:1220-7.

26. Strzempko Butt F, Chesla C. Relational patterns of couples living with chronic pelvic pain from endometriosis. Qual Health Res 2007;17:571-85.

27. Culley L, Law C, Hudson N, et al. A qualitative study of the impact of endometriosis on male partners. Hum Reprod 2017;32:1667-73.

28. Laws S. Issues of Blood: The Politics of Menstruation. Springer 1990.

29. Dowlut-McElroy T, Strickland JL. Endometriosis in adolescents. Curr Opin Obstet Gynecol 2017;29:306-9.

30. Matalliotakis M, Goulielmos GN, Matalliotaki C, et al. Endometriosis in Adolescent and Young Girls: Report on a Series of 55 Cases. J Pediatr Adolesc Gynecol 2017;30:568-70.

31. Sadler Gallagher J, Feldman HA, Stokes NA, et al. The Effects of Gonadotropin-Releasing Hormone Agonist Combined with AddBack Therapy on Quality of Life for Adolescents with Endometriosis: A Randomized Controlled Trial. J Pediatr Adolesc Gynecol 2017;30:215-22.

32. Sarıdoğan E. Adolescent endometriosis. Eur J Obstet Gynecol Reprod Biol 2017;209:46-9.

33. Sarıdoğan E. Endometriosis in teenagers. Womens Health 2015;11:705-9.

34. Parker MA, Sneddon AE, Arbon P. The menstrual disorder of teenagers (MDOT) study: determining typical menstrual patterns and menstrual disturbance in a large population-based study of Australian teenagers. BJOG: An International Journal of Obstetrics \& Gynaecology 2010;117:185-92.

35. Martin CE, Houston AM, Mmari KN, et al. Urban teens and young adults describe drama, disrespect, dating violence and help-seeking preferences. Matern Child Health J 2012;16:957-66.

36. Larson NI, Wall MM, Story MT, et al. Home/family, peer, school, and neighborhood correlates of obesity in adolescents. Obesity 2013;21:1858-69.

37. Mayberry ML, Espelage DL, Koenig B. Multilevel modeling of direct effects and interactions of peers, parents, school, and community influences on adolescent substance use. J Youth Adolesc 2009;38:1038-49.

38. Stone AL, Becker LG, Huber AM, et al. Review of risk and protective factors of substance use and problem use in emerging adulthood. Addict Behav 2012;37:747-75.

39. Kotchick BA, Shaffer A, Forehand R, et al. Adolescent sexual risk behavior: a multi-system perspective. Clin Psychol Rev 2001;21:493-519.

40. Steinberg L. Adolescence. 2016 http://www.mheducation.com/ highered/product/adolescence-steinberg/M1259567826.html (accessed 3 Sep 2017).

41. Horne AW, Saunders PTK, Abokhrais IM, et al. Top ten endometriosis research priorities in the UK and Ireland. Lancet 2017;389:2191-2.

42. Dunselman GA, Vermeulen N, Becker C, et al. ESHRE guideline: management of women with endometriosis. Hum Reprod 2014;29:400-12.

43. Bronfenbrenner U. Toward an experimental ecology of human development. Am Psychol 1977;32:513-31.
44. Barter C, Renold E. 'I wanna tell you a story': Exploring the application of vignettes in qualitative research with children and young people. Int J Soc Res Methodol 2000;3:307-23.

45. Hughes R, Huby M. The application of vignettes in social and nursing research. J Adv Nurs 2002;37:382-6.

46. Atlas.ti 7. Germany:: Scientific Software Development, 2013.

47. Mays N, Pope C. Rigour and qualitative research. BMJ 1995;311:109-12.

48. Miles MB, Huberman AM, Saldaña J, et alSAGE 2013.

49. Ulin PR, Robinson ET, Tolley EE. Qualitative methods in public health a field guide for applied research. 1st ed. San Francisco, CA: JosseyBass, 2005.

50. Onwuegbuzie AJ, Dickinson WB, Leech NL, et al. A Qualitative Framework for Collecting and Analyzing Data in Focus Group Research. Int J Qual Methods 2009;8:1-21.

51. Glaser BG, Strauss AL, Strutzel E. The Discovery of Grounded Theory; Strategies for Qualitative Research. Nurs Res 1968;17:364 https://journals.Iww.com/nursingresearchonline/Citation/1968/ 07000/The_Discovery_of_Grounded_Theory_Strategies_for.14. aspx.

52. Rodgers BL, Cowles KV. The qualitative research audit trail: a complex collection of documentation. Res Nurs Health 1993;16:219-26.

53. Denny E, Mann CH. Endometriosis-associated dyspareunia: the impact on women's lives. J Fam Plann Reprod Health Care 2007;33:189-93 http://dx.doi.org.mutex.gmu.edu/.

54. Haberland NA. The case for addressing gender and power in sexuality and HIV education: a comprehensive review of evaluation studies. Int Perspect Sex Reprod Health 2015;41:31-42.

55. Reed E, Silverman JG, Raj A, et al. Male perpetration of teen dating violence: associations with neighborhood violence involvement, gender attitudes, and perceived peer and neighborhood norms. $J$ Urban Health 2011;88:226-39.

56. Wood K, Maforah F, Jewkes R. "He forced me to love him": putting violence on adolescent sexual health agendas. Soc Sci Med 1998;47:233-42.

57. Casteel C, Martin SL, Smith JB, et al. National study of physical and sexual assault among women with disabilities. Inj Prev 2008;14:87-90.

58. Stöckl H, Heise L, Watts C. Factors associated with violence by a current partner in a nationally representative sample of German women. Sociol Health IIIn 2011;33:694-709.

59. Young K, Fisher J, Kirkman M. Women's experiences of endometriosis: a systematic review and synthesis of qualitative research. J Fam Plann Reprod Health Care 2015;41.

60. Bulanda JJ, Bruhn C, Byro-Johnson T, et al. Addressing mental health stigma among young adolescents: evaluation of a youth-led approach. Health Soc Work 2014;39:73-80.

61. Mahajan AP, Sayles JN, Patel VA, et al. Stigma in the HIV/AIDS epidemic: a review of the literature and recommendations for the way forward. AIDS 2008;22 Suppl 2(Suppl 2):S67-79.

62. Miller E, Tancredi DJ, McCauley HL, et al. One-year follow-up of a coach-delivered dating violence prevention program: a cluster randomized controlled trial. Am J Prev Med 2013;45:108-12.

63. Quinceañera | celebration | Britannica.com. 2018 https://www. britannica.com/topic/quinceanera (accessed 16 Feb 2018). 